Vantage: Journal of Thematic Analysis

ISSN: 2582-7391

A Multidisciplinary Publication of Centre for Research, Maitreyi College, University of Delhi

October 2021, Volume 2, Issue 2

Editorial

\title{
Sustainable Agriculture: Negotiating Tradition and Modernity
}

It has been projected that by the year 2050, the global population will reach 9.3 billion. By implication, this means that food production has to increase from 8.4 billion tonnes to 13.4 billion tonnes in order to keep pace with this increase (Food and Agriculture Organization of the United Nations, 2014), and also, that the already existing land, water, and energy crisis will possibly get further intensified. The crucial question is: Are we ready to deal with this? Clearly, we are amidst an agricultural crisis, wherein the ability of agriculture to fulfil human needs is threatened by factors such as climate change, loss of biodiversity, land degradation through soil erosion, compaction, salinization and pollution, depletion and pollution of water resources, rising production costs, poverty and a decrease of the rural population (Velten et al., 2015).

Agricultural practices have changed over time due to technological advancements in the agriculture sector in the nineteenth century and the introduction of genetic engineering and other techniques in the late 20th century. This is in contrast to the traditional practices that are grounded in traditional, indigenous knowledge and cultural beliefs. In traditional practice the production process is geared for subsistence and not the market, whereas modern agriculture practices are grounded in the epistemology of the physical sciences such as the use of modern scientific methods and rapid technological innovations, leading to faster and increased production in lesser time, driven by profit motive and geared towards the market. These practices not only represent differences in technology, but also two distinct ways of apprehending the world and the relationship between man and nature. Underlying the traditional system of agriculture is the perception of a continuity between man and nature, in which natural resources, including the earth are perceived as an extension of the self. Hence, care of the natural resources by way of worshipping them

Vantage: Journal of Thematic Analysis, 2021; 2(2): 1-3 
among other things, is inherent in the process of cultivation. The process of modernization gradually led to an increasing alienation of man from nature.

The "Green Revolution" in the 1960's enhanced the agricultural productivity in South East Asia manifold by the increased use of chemical fertilizers and insecticides, high yielding quality seeds, irrigation and mechanization. The primary aim was to alleviate poverty and malnutrition (Nelson et al., 2019). 'Not to deny, the green revolution was capable of mitigating hunger and malnutrition in the short term as well' (Davis et al., 2019). It was argued that besides providing food, it helped in preserving large areas of forests that otherwise would have been converted into farmland. However, soon enough, some unintended but adverse effects of the green revolution became evident and raised serious concerns about the long-term sustainability of this conventional chemical-based system.

Striking a balance between food security, for ever increasing human population and safety of natural resources, hence, became and continues to be a major concern. There is an increasing need to revisit the prevalent agricultural practices and search for alternatives.

The idea of a sustainable agriculture gained prominence with the publication of the Brundtland Report in 1987, which defines sustainable development as that "which meets the needs of the present without compromising the ability of future generations to meet their own needs." A strong and sustainable agricultural sector is imperative to meet these goals. However, the concept of sustainable agriculture is complex and contested. There are varied discourses on sustainable agriculture and numerous attempts to define it. However, a common thread runs through these varied definitions, which provides a framework to view sustainable agriculture as that which is socially acceptable, economically viable and environmentally sound.

Emerging as a critique of conventional farming, sustainable agriculture embodies the possibility of a negotiation between the modern and traditional methods. It includes a number of alternative practices such as agroecology, nature exclusive agriculture, permaculture, biodynamic agriculture, organic farming, conservation agriculture etc., which draw on different traditional practices. These practices are like a basket of choices of different ways to attain sustainability. It is important that the farmers be educated about 
these to enable them to make informed choices about the practices they want to pursue. As Bill Gates famously said, "innovations that are guided by smallholder farmers, adapted to local circumstances, and sustainable for the environment and economy will be necessary to ensure food security in the future."

However, the challenges are several: sustainable practices are usually costly, in terms of knowledge and labour, they require public and government support in the form of loans and subsidies to encourage farmers to practice sustainable agriculture, lack of awareness among consumers, to mention a few. There is a need to develop a framework to understand the components of sustainable agriculture and highlight ways in which the stakeholders can deal with the complexity and multiplicity of this concept in a constructive manner.

Gopi Devdutt Tripathy, Brototi Roy and Meena Yadav

\section{References}

Davis, K. F., Chiarelli, D. D., Rulli, M. C., Chhatre, A., Richter, B., Singh, D., et al. (2018). Alternative cereals can improve water use and nutrient supply in India. Science Advances. 4:eaao1108. https://doi.org/10.1126/sciadv.aao1108

Food and Agriculture Organization of the United Nations (2014). Building a common vision for sustainable food and agriculture: Principles and approaches. Retrieved from https://www.fao.org/3/i3940e/i3940e.pdf

Nelson, A. R. L. E., Ravichandran, K., \& Antony, U. (2019). The impact of the Green Revolution on indigenous crops of India. Journal of Ethnic Foods 6, 8. https://doi.org/10.1186/s42779-019-0011-9

Our Common Future (Brundtland Report) (1987). Report of the World Commission on Environment and Development. Retrieved from: https://www.are.admin.ch/ are/en/home/media/publications/sustainable-development/brundtland-report.html

Velten, S., Leventon, J., Jager, N. W., \& Newig, J. (2015). What is sustainable agriculture? A systematic review. Sustainability, 7(6), 7833-7865.

How to cite this article: Editorial. Sustainable Agriculture: Negotiating tradition and modernity. Vantage: Journal of Thematic Analysis, 2(2): 1-3

DOI: https://doi.org/10.52253/vjta.2021.v02i02.01

(C) The Author(s) 2021.

This work is licensed under a Creative Commons Attribution 4.0 International License which permits its use, distribution and reproduction in any medium, provided the original work is cited.

Vantage: Journal of Thematic Analysis, 2021;2(2): 1-3 